\title{
esboços
}

histórias em contextos globais

\section{EXPOSIÇÃO DE CRIANÇAS E TRAVESSIAS ATLÂNTICAS: \\ O TRÂNSITO DE PRÁTICAS E PESSOAS PARA O EXTREMO SUL DA AMÉRICA PORTUGUESA (1750-1810)}

Children's exposure and Atlantic crossings: the passage of practices and people to the extreme south of Portuguese America (1750-1810)

Jonathan Fachini da Silva ${ }^{a}$

(1) https://orcid.org/0000-0002-0258-288X

E-mail: j_fachini@hotmail.com

a Serviço Social da Indústria, Educação de Jovens e Adultos a Distância, Cachoeirinha, RS, Brasil 


\title{
RESUMO
}

A exposição de crianças foi um fenômeno comum no universo católico do período moderno. Amplamente praticado e tolerado em território ibérico, o episódio assumiu novas proporções com as expansões europeias, a partir do século XVI, chegando na bagagem do colonizador aos novos espaços territoriais. É justamente no intuito de perceber a expansão dessa prática que o presente artigo analisa as travessias atlânticas de expostos, os quais, enjeitados em Lisboa na infância, sobreviveram, cresceram e partiram para a América Portuguesa, onde se estabeleceram. Amparados na História Social e com um aporte teórico inspirado na micro-história italiana, percebemos como essas trajetórias podem trazer luz sobre a temática da exposição de crianças, a difusão de sua prática, nos dois lados do Atlântico.

\section{PALAVRAS-CHAVE}

Expostos. Atlântico. Porto Alegre.

\begin{abstract}
The exposure of children was a common phenomenon in the Catholic universe of the modern period. Widely practiced and tolerated in Iberian territory, the phenomenon took on new proportions with European expansions, starting in the 16th century, arriving along with the colonizer in the new territorial spaces. It is precisely in order to perceive the expansion of this practice that this article analyzes the Atlantic crossings of exposed people, who were rejected in Lisbon in their childhood, survived, grew up and travelled to Portuguese America, where they settled. With the support of Social History and a theoretical contribution inspired by Italian micro history, we realized how these trajectories can shed light on the theme of children's exposure, the spread of this practice, on both sides of the Atlantic.
\end{abstract}

\section{KEYWORDS}

Exposed. Atlantic. Porto Alegre. 
ato de abandonar bebês remonta a um passado longínquo, pelo menos na história Ocidental. Mesmo que pesem os significados atribuídos a tal prática e os contextos específicos de cada momento histórico, trata-se de um fenômeno de longa duração. Aqui queremos tratar de um desses momentos, o período moderno em que ganhou força esta prática, conforme a nomenclatura adequada, de expor ou enjeitar bebês. Nesse caso, não se tratava exatamente de um abandono, de acordo com a acepção contemporânea da palavra, e sim de abdicar da criação de um filho ou uma filha, enjeitando essa criança, geralmente na tenra idade, na porta de um domicílio, de igrejas ou de conventos.

No Dicionário da Língua Portuguesa, de Antônio de Morais Silva, a palavra "exposto" aparece como uma derivação do verbo latino exponére, que significa, entre as várias acepções, "expor uma criança, enjeitá-la; expor a vida, arriscá-la, pô-la em perigo" (SILVA, 1798, p. 801). Também no Vocabulário Português e Latino, de Raphael Bluteau, no início do século XVIII, no tomo de adágios, o verbete enjeitado aparece como

[...] menino enjeitado, é o que desamparado de seus pais, e exposto no adro de uma Igreja, ou deixado no limiar de um Convento, ou de pessoa particular, ou depositado no campo a Deus, e à ventura, cruelmente padece o castigo dos ilícitos concubinatos de seus pais. Para obviar a crueldade deste infanticídio, e a inumana desconfiança de alguns, cuja pobreza os obriga a este desatino, por não ter com que alimentar família mais numerosa, em muitas partes da cristandade há hospitais com Rodas, onde se põem as tristes criaturas, e se dão a criar mulheres escolhidas, e aceiradas para este efeito (1727, p. 577).

O verbete de Bluteau sintetiza a exposição no âmbito teórico por parte de muitos moralistas e juristas do século XVIII e XIX. Muitos dos que enjeitaram seus filhos no período moderno poderiam ter conhecimento do paradeiro da criança e contato com ela ou a intenção de resgatá-la posteriormente. Entretanto, esse fenômeno se dava nas relações cotidianas, pois o anonimato de quem enjeitava a criança era essencial para essa prática (FRANCO, 2014, p.101-109; SÁ, 2013, p. 121-123).

Ao fim da Idade Média, a exposição ou o enjeitamento de bebês era um fenômeno tão abrangente na Europa católica que surgiram instituições de abrigo a essas crianças, conventos e hospitais que instalaram em suas estruturas a famosa roda dos expostos. ${ }^{1}$

Em Portugal, o assistencialismo à criança abandonada esteve atrelado a um espírito caritativo desenvolvido no pensamento cristão, fazendo com que Casas de Misericórdia abrigassem os pequeninos abandonados. Os códigos portugueses, desde as Ordenações Manuelinas do século XVI, obrigavam as câmaras municipais a custear a alimentação e a criação dos enjeitados, contratando criadeiras e amas

\footnotetext{
${ }^{1}$ O nome "roda", dado por extensão à casa dos expostos, provém do dispositivo de madeira no qual se depositava o bebê. De forma cilíndrica e com uma divisória no meio, era fixado no muro ou na janela da instituição. No tabuleiro inferior da parte externa, o expositor colocava a criancinha, girava a roda e puxava um cordão com uma sineta para avisar à vigilante, ou rodeira, que um bebê acabara de ser abandonado, retirando-se furtivamente do local, sem ser reconhecido (MARCÍLIO, 1998, p. 56).
} 
de leite para os cuidados necessários com essas crianças. Ao longo do século XVII e XVIII, as câmaras municipais passaram a responsabilidade da assistência aos expostos para as Misericórdias locais, continuando, no entanto, a subvencioná-las (SÁ, 1995).

No lado de cá do Atlântico, a prática da exposição de crianças claramente esteve atrelada à colonização portuguesa, bem como a assistência a essas crianças conforme as legislações portuguesas estendidas a suas colônias, uma forma dialética entre o abandono de crianças por parte da população que constituía as freguesias e a assistência por parte das autoridades da municipalidade colonial. O tema já teve amplo estudo por especialistas como Maria Luiza Marcílio (1998) e Renato Venancio (1999), além de estudos recentes, como o de Renato Franco (2014), que tem demonstrado todos os entraves da assistência aos expostos e a dificuldade das autoridades municipais de seguirem à risca a responsabilidade de financiar auxílios aos expostos ou mesmo das Misericórdias em colocarem em funcionamento rodas de expostos ou a casa da roda para atender essas crianças.

Dado esse pequeno contexto, nossa intenção neste texto é mostrar como a exposição de crianças esteve atrelada ao processo de colonização e de assistência implantado pelo projeto da Coroa portuguesa. A proposta é identificar que, junto com o trânsito de pessoas pelo Atlântico, práticas como a de enjeitar crianças também alcançaram novas formas e contextos, adequando-se a esses espaços. Para atingirmos nosso objetivo, partimos de um minucioso cruzamento de fontes legislativas e das Misericórdias - eclesiásticas e cartoriais, de ambos os lados do Atlântico -, mapeando esparsas trajetórias que nos dizem muito sobre esse hábito que circulou pelo Império português.

O texto, dessa forma, se divide em dois momentos. O primeiro deles, durante o período de expansão portuguesa, procurando observar concomitantemente a essa expansão a das Misericórdias e a assistência a pobres e enjeitados. Depois, procuramos mostrar como o trânsito de pessoas acabou por reproduzir tais ações, pois, mesmo aqueles que tiveram a infância marcada por esse fenômeno, quando adultos, migraram para a América portuguesa em busca de melhores condições e reproduziram essas mesmas práticas. Trata-se de trajetórias de expostos que migraram para o extremo sul da América portuguesa, especificamente a freguesia Madre de Deus de Porto Alegre, sede da capitania do Rio Grande de São Pedro, região de colonização tardia, mas que, a partir de meados do século XVIII, apresentou um crescimento demográfico e urbano acelerado graças a conexões portuárias e defesas naturais numa fronteira de intenso conflito com os espanhóis.

\section{UMA PRÁTICA EM EXPANSÃO: MISERICÓRDIAS E ASSISTÊNCIA}

Trabalhos consagrados nos dois lados do Atlântico sobre a temática do abandono de crianças no período moderno já nos deram bases suficientes para nos dizer que a posição colonial, a mestiçagem e a ilegitimidade pouco nos ajudam a entender a complexidade desse fenômeno (FRANCO, 2019). Nesse caso, uma perspectiva que nos parece promissora é levar em consideração um contexto mais global das políticas públicas implantadas em prol do acolhimento dessas crianças tanto em Portugal quanto no restante da Europa nesse período. 
Entendido dessa maneira, mais do que mapear os expostos e sua inserção social, deve-se problematizar como a própria colonização portuguesa no sul do Brasil, em âmbito governativo, religioso e social, pôde ganhar novas dimensões e quais significados foram acionados por essa assistência aos expostos.

Se procuramos traçar as especificidades do local sem perder os contextos mais amplos, numa variação de escala, é de grande valia analisar uma perspectiva Atlântica. Aqui, temos de reservar um espaço para alguns esclarecimentos sobre nosso viés de análise, percebendo as conexões estabelecidas e possibilitadas pela navegação no Atlântico. Hoje, historiadores têm discutido e procurado percebê-lo como um campo de nossa área, o que denominam como uma atlantic history. Num esforço de classificação dessa tendência historiográfica britânica, David Armitage classifica a história atlântica em três categorias que se relacionam: a circum-atlântica, a cisatlântica e, a mais significativa para o nosso caso, a transatlântica. Em suas palavras, a última ficaria da seguinte forma:

O sistema de circulação do Atlântico criou ligações entre regiões e pessoas antes separadas. Isso permitiu aos historiadores transatlânticos delinearem comparações significativas - e não meramente arbitrárias - entre histórias que seriam, de outro modo, distintas (2014, p. 217).

Optamos aqui por analisar a história transatlântica não como um campo específico de pesquisa, como quer Armitage (2014), nem como método de análise. Ao contrário, incorporamos alguns elementos que nos inspiram a pensar a circulação de ideias e pessoas no mundo atlântico. Essa óptica nos remete a trabalhos consagrados da historiografia sobre o Império português e ao trânsito de pessoas no Atlântico sul. ${ }^{2}$ Não é por menos que Armitage (2014, p. 215) deixa bem claro que essa análise "impulsiona os historiadores em direção a um pluralismo metodológico e horizontes mais amplos".

Com essa discussão, o que salientamos é que não podemos pensar a Região Sul do Brasil sem levar em conta suas conexões com o Atlântico e com a região platina, onde mercadorias, pessoas, ideias e conhecimentos circulam e se conectam. Assim, se a exposição de crianças chegou pelo Atlântico, também as práticas de assistência vieram das ordenações do reino, implementadas no ultramar, até as medidas filantrópicas do século XIX - ideias importadas do outro lado do Atlântico e que serviram para inspirar os legisladores brasileiros.

Por esse caminho, pensar o século XVIII pressupõe levar em consideração um emaranhado de conexões e transitoriedades. Essa visão tem sido cada vez mais frutífera, e, apesar de um campo em aberto e em disputa, trabalhos pioneiros já trouxeram à tona essa concepção, como mencionamos antes. Russell-Wood destacava que o movimento dos portugueses pela África, pela América e pela Ásia fez com que diversos povos tivessem a percepção da "existência uns dos outros", o que

\footnotetext{
${ }^{2}$ Referimo-nos ao estudo de Alencastro (2000), que já demonstrava a interdependência das duas margens do Atlântico sul desde o fim do século XVI. Nesse caso, constituiu-se um espaço territorial único. Os enclaves portugueses na América e as feitorias angolanas eram um só sistema de exploração colonial. O mesmo vale para os trabalhos clássicos dos brasilianistas Charles Boxer e, depois, de seu pupilo e seguidor Anthony Russell-Wood (2006). Ambos acrescentaram o Índico e o Oriente a suas contribuições.
} 
alterou hábitos de consumo, culinária, técnicas e os produtos do meio agrário, num constante "fluxo e refluxo" de mercadorias, agentes administrativos, escravizados, degredados, espécies vegetais e animais (DOMINGUES; MOURA, 2014, p. 11-12).

\begin{abstract}
O facto de ter escolhido o movimento como tema subjacente e unificador, permitiu-me abordar a exploração e a descoberta, os veículos de transporte de pessoas e de mercadorias através de continentes e de oceanos, as diásporas humanas e as migrações forçadas, os padrões e a dinâmica do comércio, a dispersão global de doenças, de plantas e de exemplares da fauna, a transmissão cultural de estilos e de hábitos e, por fim, a comunicação, a difusão e a troca de ideias entre os povos. A universalidade deste tema unificador foi libertadora uma vez que me deixou livre, para atravessar oceanos, para me deslocar de um continente para o outro fugindo, dentro dos limites razoáveis, à tirania da cronologia (RUSSELL-WOOD, 2006, p. 17).
\end{abstract}

A tônica de nosso referencial teórico-metodológico, num primeiro momento, parece não se corresponder, de um lado priorizando a redução de escala da microhistória e, de outro, contextos mais amplos com a história atlântica. Apesar disso, pesquisadores contemporâneos têm aproximado esses dois pontos de vista e trazido bons resultados. Rebecca Scott e Jean Hébrard (2014), por exemplo, acompanharam as viagens de uma família - os Vincent/Tinchant - por três continentes. A trajetória dessa família, num esquema genealógico, nos revela como ela procurou fugir do racismo, apagando seu passado escravo, reelaborando sua história e identidade. Discutindo temas como escravidão e liberdade, traçando trajetórias e colocando rostos aos sujeitos históricos tratados ao longo do trabalho, os autores denominaram seu método de uma micro-história posta em "movimento" (SCOTT; HÉBRARD, 2014).

É sob esse mesmo prisma que Lara Putnam, em suas pesquisas sobre a propagação do anti-imperialismo no período entre as guerras britânicas no Caribe no fim do século XIX e início do XX, aponta aproximações entre a micro-história e a história atlântica. Para Putnam, o método de ambas as perspectivas se aproxima na medida em que procuram estabelecer conexões, antes negligenciadas, pelo cruzamento de uma gama de documentos analisados. A prosopografia, para Putnam (2006), é um método em comum e dá rosto aos sujeitos históricos em espaços geográficos mais alargados, embora muito bem definidos.

Sem perder de vista as singularidades do contexto, em alguns momentos procuramos redimensionar nosso espaço geográfico de maneira mais ampla. Se bem que pareça um esgarçamento da micro-história, suas características comuns são preservadas em nossa pesquisa, como a utilização de grande (e diversa) quantidade de fontes históricas, uma análise minuciosa sobre esses documentos e a variação de escala na tentativa de não cair em generalizações, e, na medida do possível, oferecer respostas locais a questões gerais. Além da variação de escala, o cruzamento nominativo de fontes é essencial no que tange aos aspectos metodológicos. Assim, o nome é nosso fio condutor, ou fio de Ariadne, conforme expressão sugerida por Carlo Ginzburg (2007). ${ }^{3}$

\footnotetext{
${ }_{3}^{3}$ Trata-se de uma metáfora usada por Ginzburg (2007) referente ao mito grego em que Teseu recebe de
} 
Feitas essas observações, podemos partir do pioneiro trabalho de Charles Boxer, que será nossa base para iniciar a discussão que se seguirá. No tópico "Conselheiros municipais e irmãos de caridade", o autor afirma a máxima de que "a Câmara e a Misericórdia podem ser descritas, com algum exagero, como os pilares gêmeos da sociedade colonial portuguesa do Maranhão até Macau" (2002, p. 282). Se assumirmos tal afirmação, entenderemos que essas duas instituições são basilares para a administração portuguesa e garantiam uma continuidade ao processo de colonização. Nesse caso, o importante a destacar é que ambas tiveram relações diretas com a prática da exposição de crianças, haja vista que assistiam os enjeitados.

As Câmaras municipais eram os sustentáculos da monarquia portuguesa, pois, por meio delas, o rei (cabeça) estendia como tentáculos (as Câmaras) a dimensão do poder real. Fernanda Bicalho, ao tratar da Câmara no Rio de Janeiro, traçou paralelos com as existentes em Goa e Macau, advertindo que:

[...] cada câmara - reinol e ultramarina - tinha uma configuração própria e um equilíbrio historicamente tecido ao longo do tempo e das diferentes conjunturas econômicas, sociais e políticas no amplo espaço geográfico da monarquia portuguesa no Antigo Regime (2001, p. 193).

Mesmo com configurações próprias que poderiam variar conforme o espaço e o contexto, eram essas instituições as responsáveis, em última instância, por angariar fundos para a contratação de amas de leite e de criação para com os cuidados e os bons tratos dos pequenos enjeitados. Essa prerrogativa estava valendo desde as Ordenações Manuelinas (1512-1521). Na América portuguesa - ou, invariavelmente, como ocorria em outras regiões do Império português -, as Câmaras municipais se eximiam dessa responsabilidade, queixando-se às autoridades de quão oneroso eram os custos com os enjeitados (MARCÍLIO, 1998, p. 139-140).

As misericórdias também tiveram papel fundamental para a assistência aos expostos. O acolhimento aos enjeitados estava regimentado dentro de seus compromissos. O Compromisso da Misericórdia de Lisboa, impresso em 1516, se tornou um modelo adaptado às Misericórdias ultramarinas, no qual o auxílio aos enjeitados estava inserido indiretamente nas obras corporais. ${ }^{4}$ Entretanto, após uma reforma desse compromisso, em 1577 e 1618, os expostos passaram a estar diretamente mencionados para o alcance de caridade (SÁ, 2013, p. 122).

Ainda que a casa da Misericórdia se não cullmina encarregar dos meninos engeitados [...] Achandose alguns meninos dessa calidade, constando de seu desamparo, o Provedor, se mais

\footnotetext{
Ariadne um fio que o orienta pelo labirinto, onde encontrou e matou o minotauro. Desse modo, o nome é o fio que nos orienta pelo cruzamento de fontes, a fim de reconstituir a história dessas crianças que foram expostas no extremo sul da América portuguesa.

${ }^{4}$ Laurinda Abreu (2017, p. 249) menciona que essas "reformas do compromisso da Misericórdia de Lisboa, de 1577 e de 1618, realizadas num contexto dinâmico em termos destas políticas sociais, expressam a necessidade de adaptação das confrarias às múltiplas mudanças em curso, detectáveis, por exemplo, no aumento do número dos irmãos e alargamento das suas responsabilidades, nas maiores preocupações ao nível da especificação das diferentes funções, numa mais rigorosa vigilância dos alvos de caridade".
} 
irmãos da mesa os mandarão acabar de criar mandolhe amas, em quanto forem de pouca idade, e depois de crescidos lhes darão ordem conveniente, para que nem por falta de ocupação fiquem expostos aos males que a ociosidade costuma causar (BNP, 1640, p. 36-37).

É importante reforçar que, além das práticas de assistência a pobres e enfermos, as Misericórdias desempenharam um papel importante no jogo dos poderes políticos. Laurinda Abreu (2017, p. 245-277) salienta que, nesse âmbito, essas instituições mantiveram a autonomia nas comunidades locais e se tornaram um poder institucional em meio a um jogo disputado entre o poder central e local.

Mesmo leigas, as confrarias das Misericórdias estavam vinculadas à prática cristã, ligadas diretamente ao catolicismo ibérico. Em estudo sobre Goa, na Índia, Ângela Xavier (2008, p. 356) aponta como as Misericórdias, junto com outros dispositivos assistenciais e de conversão, como as missões, na medida em que beneficiaram as comunidades locais, se transformaram em mais um mecanismo para o processo de cristianização daquelas populações. Com a manutenção desses mecanismos, elas mantinham a conservação e a reprodução das instituições e da cultura dominante.

Entendemos melhor as afirmações sobre os mecanismos de assistência como aparatos para a colonização portuguesa quando observamos as Misericórdias na Ásia, na África, no Brasil e nos Açores desde o século XVI. Podemos citar alguns exemplos, como Goa (1519), Santos (1543), Salvador (1552), Macau (1569), Luanda (1576), Rio de Janeiro (1582) e Mombaça (1593). Outros exemplos de Misericórdias seiscentistas são encontrados na Ásia, como Colombo (Sri Lanka), Cochin, Chaul, Diu, Malaca, Ormuz e São Tomé de Meliapor (COATES, 1998, p. 45).

Em muitas áreas do extenso território de domínio português, podemos observar que os expostos foram acolhidos pelas Santas Casas. Um exemplo é o compromisso da Misericórdia de Goa, de 1595, no qual é possível identificar uma leitura do capítulo 33 do compromisso da Misericórdia de Lisboa. No capítulo 34 do compromisso da Misericórdia de Goa, consta que

\begin{abstract}
Os meninos cujas mães adoecem e não os podem criar nem dar a criar por sua pobreza ou falecendo elas, ficam desamparados, ou têm necessidade de alguma ajuda para sua criação, estes proverão nesta Casa na maneira que parecer ao provedor e irmão. Vindo alguns enjeitados a esta Casa da Misericórdia se dará a criar como até agora se fez, com o dinheiro que para isso dá a cidade (SEABRA, 2005, p. 70).
\end{abstract}

Em outras regiões do Oriente também houve a recorrência da prática da exposição de crianças. Em Macau, por exemplo, a Misericórdia, já em 1571, assistia os enjeitados em suas dependências, sem distinção étnica, sendo a grande maioria deles chineses, órfãos e cativos, e enfermos pobres (SEABRA, 2007, p. 608). Também podemos encontrar a recorrência de expostos na África. Em Moçambique, já no século XIX, a Irmandade da Santa Casa solicitava recursos ao governador capitão-general para manter suas "atividades piedosas que executa, tais como, o Hospital para Pobres, Casa de Roda dos Expostos e Hospital de Mulheres Pobres e faltando recursos para os manter" (AHU, 1830). Em Angola, houve conflitos entre as Misericórdias 
estabelecidas desde meados do século XVII. Os moradores da Vila da Vitória de Massangano pediam licença à Coroa, por meio do Conselho Ultramarino, para fazer a obra de uma casa e um hospital da Irmandade de Santa Casa de Misericórdia, a fim de tratar "os enfermos e as viúvas sem amparo", apesar da oposição da Santa Casa da Misericórdia de São Paulo da Assunção, que afirmava "que o provedor e os irmãos dela agiam apenas em defesa dos seus interesses, sem pensar no serviço de Deus e de Sua Majestade" (AHU, 1661).

$\mathrm{Na}$ América portuguesa, as Misericórdias foram fundadas dos séculos XVI ao XIX, de norte a sul do território. Renato Franco, num estudo aprofundado sobre o tema, contabilizou 22 instituições. O autor destaca que as Misericórdias, no espaço luso-brasileiro, foram resultado de "um processo descontínuo e nem sempre obedeceu aos ditames do dinamismo econômico", o que acarretava uma precarização da rede assistencial, a qual deixava irregular a abrangência de suas ações até pelo menos o século XVIII (2011, p. 95).

Sobre a assistência aos expostos, algumas Misericórdias fizeram parcerias com as Câmaras. Foi o caso das Câmaras do Rio de Janeiro e de Salvador. Mas queixas e orientações vindas do Conselho Ultramarino são bastante ilustrativas de como a governança local resistia a custear os expostos ou somava dívidas exorbitantes nos repasses dos salários às amas (FRANCO, 2011; RUSSELL-WOOD, 1981).

No caso do Rio Grande de São Pedro, por exemplo, eram as Câmaras as principais instituições de amparo aos expostos. A pedra fundamental do edifício que viria a ser a Misericórdia é de 1803. Após uma discussão sobre se ele se tornaria um hospital militar ou uma Santa Casa, esta prevaleceu (WADI, 2002, p. 40-41). Em 1814, foi regulamentada a Misericórdia e, em 5 de janeiro de 1815, deliberado o deputado, escrivão da Junta da Real Fazenda, Antônio Caetano da Silva, para o cargo de mordomo dos expostos (LIVRO I DE ATAS DA MESA ADMINISTRATIVA, 1815, fl. 3v).

A Misericórdia de Porto Alegre proveu o cargo de mordomo de expostos amparada no Alvará Régio de 1806, o qual regulou seu compromisso. No artigo $7^{\circ}$ do referido documento, é atribuído às Misericórdias o cuidado para com os expostos e, dessa forma, eleito um Irmão para ocupar o cargo e assumir tal responsabilidade. No caso de Porto Alegre, como percebemos em estudo anterior, a Misericórdia pouco interferiu na administração da exposição, sendo a Câmara a principal responsável até a criação da roda, em 1838. Ainda carecemos de estudos voltados a uma análise aprofundada sobre essa Misericórdia e a composição social dos seus irmãos nos seus primeiros anos. O que percebemos em nossa primeira pesquisa é que se trata de um mesmo grupo dirigente, tanto os que administravam a Misericórdia quanto os que detinham o aparelho público, a Câmara Municipal.

Para além da diversidade de resoluções administrativas em relação aos custeios com a criação dos enjeitados, a prática de expor crianças acontecia junto com os mecanismos de proteção social do Estado português. Assim, ela se fez presente nesses territórios, ou seja, foi expandida nesse processo de domínio cultural.

Ainda nos cabe um último enfoque: a relação da exposição de crianças, ou melhor, a relação da assistência com o catolicismo, num contexto de reforma religiosa e contrarreforma. Isabel dos Guimarães Sá mapeia algumas dessas diferenciações da assistência e da prática da caridade quanto aos enjeitados entre a Europa católica e a protestante. A autora salienta que o primeiro ponto é que o batismo para os protestantes não tinha a mesma importância que para os católicos. O limbo havia 
deixado de existir; a ênfase religiosa estava na purificação da alma, e não na vida eterna adquirida pelo batismo (SÁ, 1998, p. 13).

Outro ponto de divergência importante entre católicos e protestantes diz respeito às formas de assistência. No universo católico, a prática da caridade era essencial à conduta dos fiéis, de modo que estava muito mais dependente de ações individuais e legados testamentários. No caso protestante, criou-se um sistema mais organizado, em que cada localidade era responsável pela assistência aos pobres de sua jurisprudência - caso da Inglaterra (SLACK, 1995).

\section{AEXPOSIÇÃO DE CRIANÇAS E OTRÂNSITO DE PESSOAS}

No que tange ao fenômeno da exposição de crianças, podemos perceber certas relações das periferias ultramarinas com o centro metropolitano, e, especificamente em nosso caso de estudo, alguns vínculos com Lisboa são traçados. Além das diretrizes do compromisso da Misericórdia lisboeta, que modelaram as do ultramar, como já mencionamos, o trânsito de pessoas entre Lisboa e Brasil teve a exposição de crianças como pano de fundo. ${ }^{5}$

Para termos uma dimensão dessas conexões, trataremos de uma proposta dos mordomos da Real Casa dos Expostos enviada à mesa administrativa em 17 de novembro de 1779. A proposta de inspiração iluminista era baseada no parecer do provedor da Misericórdia de Lisboa, José António de Castilho Furtado de Mendonça, que abordava, entre muitas questões, o problema dos expostos pretos e pardos. A questão aventada era que muitas dessas crianças expostas eram resgatadas na casa da roda e depois traficadas como escravas (COLEN; MANOEL, 1999). Apenas lembrando que, no Reino, a partir de 1761, um Alvará Régio havia determinado que todos os negros que chegassem a Portugal após essa data seriam livres. ${ }^{6}$ De todo modo, aqueles que eram escravos em Portugal assim permaneciam, pois somente anos mais tarde, em 1773, o mesmo monarca promulgou a chamada Lei do Ventre Livre, pela qual se estabelecera que seriam livres todos que nascessem de mãe escrava.

José António de Castilho Furtado de Mendonça alertava para o contrabando de expostos pretos e pardos. Ele enfatizou que mesmo as amas, "pessoas que os vem buscar à Casa da Roda para os criarem à custa da mesma, barbara e furtivamente os vendem, e desta sorte fazem gemer toda a vida nos grilhões do cativeiro os mesmos inocentes" (AHSCML, Avisos e Ordens da Mesa, 1779, L. 01, fl. 93v). O Provedor ainda seguiu:

\footnotetext{
${ }^{5}$ Para termos outros exemplos desse trânsito no espaço territorial sulino, podemos recorrer aos dados demográficos referentes aos matrimônios em Porto Alegre, sede da província desde sua fundação. Dos nubentes que contraíram núpcias nessa freguesia entre 1772 e 1835, cerca de $26 \%$ eram reinóis, grande parte $(80 \%)$ oriunda de Portugal. Entre as noivas, esse percentual era modesto, visto que, como solteiras, eram menos (i)migrantes - apenas 5\% eram de territórios internacionais (FREITAS, 2011, p. 143-146).

${ }^{6}$ Quaisquer escravos que desembarcassem após esse período no Reino teriam automaticamente sua liberdade concedida, sem qualquer documentação, além de um certificado emitido pelo funcionário da alfândega, declarando o nome do navio, o porto de origem e a data do desembarque (RUSSELLWOOD, 2005, p. 74).
} 


\begin{abstract}
Providência incumbida ao nosso cuidado, por cujo motivo julgo que o primeiro objeto que devo expor à Vossa Excelência é a infelicidade de alguns enjeitados pretos e pardos, que perdem a liberdade pelos mesmos meios de adquiri-la. Parece isto impossível, mas tem sucedido, e muitas vezes (AHSCML, Avisos e Ordens da Mesa, 1779, L. 01, fl. 94f).
\end{abstract}

Aliás, é importante mencionar que a legislação portuguesa assegurava ao exposto os mesmos direitos dos filhos legítimos, como a possibilidade de herdar qualquer bem via testamento. Além disso, o mais importante era que o exposto tinha a condição jurídica de livre, de modo algum podendo ser reduzido à condição de cativo, mesmo que tivesse origem escrava (SÁ, 1995). Essa resolução jurídica foi influenciada diretamente pelas leis romanas. Tratava-se de incorporações de leis sobre os expostos desde o Código Justiniano:

A criança exposta na igreja, nas ruas, ou em qualquer outro lugar, deve ficar livre, ainda mesmo que a pessoa que a reclame prove, com autenticidade, ter dela tido a propriedade. Porque, se as nossas leis, acrescenta o imperador, tem decretado que os escravos doentes, alcancem liberdade, quando desprezados por seus senhores, como há de sofrer, que os abandonados desde o berço à comiseração d'outrem, educados depois por pessoas caritativas, permaneçam debaixo do jugo da escravidão? A crueldade de tal abandono é tanto mais criminosa, quanto ella acommette sêres muito mais desgraçados (COD. JUSTINIANO, Liv. VIII, tit. 52, 1. 3 apud VAZ, 1843, p. 14).

As denúncias levadas à mesa justificavam a proposta entregue aos mordomos dos expostos para ter mais controle sobre sua entrada e, assim, evitar a escravização de crianças negras em Portugal, sanando os "perniciosos abusos, que até agora não tiveram eficaz remédio" (AHSCML, Avisos e Ordens da Mesa, 1779, L. 01, fl. 91v). José António de Castilho Furtado de Mendonça apresenta dez problemas relacionados aos expostos ao longo de seu parecer. Se o primeiro deles alertava para a escravização de expostos pardos e pretos, o terceiro falava da desorganização e da falta de controle em que estavam os livros de entradas de expostos. Nesse item do documento, 0 provedor coloca uma questão importante:

Atualmente sucede mandarem do Brasil a esta Casa buscar com grande empenho certo enjeitado, dando as precisas confrontações para a busca e para a entrega, e oferecendo logo satisfazer todas as despesas (HSCML, Avisos e Ordens da Mesa, 1779, L. 01, fl. 96v).

O provedor, em seus primeiros quatro meses no cargo, já se inteirava da precária administração da Misericórdia e formulava medidas para o controle de entradas e saídas dos enjeitados, ainda mais dos expostos pretos e pardos, sob o risco de escravização clandestina.

Essa denúncia nos apresenta possibilidades de buscar crianças enjeitadas em Lisboa com o intuito de vendê-las como escravas no Brasil. A dificuldade de provar 
empiricamente a denúncia do provedor era enorme, mas o fato de trazer a questão à tona já era de extrema pertinência. Assim, era uma possibilidade a ser levada em consideração. Era possível tratá-la como aqueles casos do "talvez" e do "poderia ser" que a bagagem empírica do historiador permitia pressupor. ${ }^{7}$ A possibilidade de escravização de expostos também foi um obstáculo a ser enfrentado pelas intuições de acolhimento no sul do Brasil - em nosso caso, as Câmaras municipais, apesar de inúmeras restrições e alvarás régios que impediam isso.

Ainda com relação ao problema do contrabando de expostos, Maria Luiza Marcílio (1998, p. 274-275) destaca que, nas rodas, não eram raros os casos de senhores reclamando filhos de suas escravas, os quais, segundo eles, haviam sido enjeitados na instituição assistencial sem o seu consentimento. Em outras situações, eles faziam as escravas enjeitarem os filhos nas instituições e se candidatar a amas de leite, que era uma forma de ludibriar a Santa Casa e receber os salários pela prestação de serviços de sua cativa. A autora ainda nos relata casos da roda de Salvador e do Rio de Janeiro, em que as amas de leite contrabandeavam expostos pardos e negros como escravos.

Após as denúncias de José António de Castilho Furtado de Mendonça, a Misericórdia de Lisboa passou a ter livros de registros específicos, tanto para amas de leite quanto para as de seco, um para os expostos brancos e outro para os não brancos. Também os termos de entrega de expostos de cor se modificaram, pois ficaram estabelecidas penas pecuniárias às amas que não entregassem as crianças sempre que a mesa dos enjeitados determinava ou após o término do período de criação. Para termos alguma dimensão demográfica dessa questão, Isabel Braga (2011) realizou uma análise quantitativa sobre os livros de entrada de expostos pretos e pardos de 1780, início dos registros, até 1807, um ano antes da partida da Corte para o Brasil. A autora calculou um total de 405 entradas de expostos pretos e pardos. Entretanto, por falta de estudos, não pôde calcular a relação de entradas desses expostos em relação aos brancos na roda. Esse cálculo foi realizado apenas para o ano de 1778, em que os expostos pretos e pardos representaram $1,5 \%$ do total de entradas.

Se observarmos, baseados nas denúncias do provedor, uma circulação de pessoas pelo Atlântico em relação à exposição, isso fica mais evidente quando percebemos que expostos, quando adultos, também atravessam, circulam e reproduzem tal prática. Assim, o outro elemento para nossa reflexão se deu pelo trânsito de expostos para as demais regiões do Império português, exclusivamente para o sul da América portuguesa.

Às oito horas da manhã do dia 4 de agosto de 1788, na Matriz de Porto Alegre, o pároco José Ignacio dos Santos Pereira dava as benções ao casamento de Gregório José da Rosa com Luisa Dezideria da Silveria. A noiva era filha legítima de Manuel da Silveira e de Ana Maria, natural da Freguesia de Nossa Senhora de Conceição de Viamão, localidade vizinha a Porto Alegre. Seus pais eram naturais dos Açores.

Sobre o fluxo de migrantes açorianos para ocupar a Região Sul, é importante mencionar que, entre 1747 e 1756, a Coroa portuguesa promoveu em larga escala a migração de casais das ilhas para ocupação e colonização do Sul do Brasil. Para termos ideia, em 1747, estavam já alistados cerca de 8 mil indivíduos, sobretudo

\footnotetext{
${ }_{7}$ Trata-se do espaço das incertezas, dos "talvez", dos "poderia ser" a que o historiador tem de recorrer quando as evidências são inadequadas ou geram perplexidade (DAVIS, 1987).
} 
oriundos das ilhas do grupo central - Faial, Graciosa, Pico, São Jorge e Terceira. Da Ilha da Madeira partiram 226 casais, num total de 1.277 pessoas (SCOTT; BERUTE, 2011, p. 107).

Quanto ao noivo, fora exposto na Santa Casa da Conceição de Lisboa (AHCMPA, Livro I de casamentos de livres, 1788, fl. 20v). Gregório, conforme consta em sua habilitação matrimonial, atuava como marinheiro. As testemunhas, predominantemente marinheiros e reinóis, interpelaram a seu favor, afirmando que era um homem solteiro e tinha vivido "até o pres[ente] de andar embarcado pela soldada de marinheiro" (AHCMPA, Habilitação matrimonial, 1788, fl.31v). As mesmas testemunhas ainda afirmaram que conheceram Gregório quando ele esteve embarcado no porto do Rio de Janeiro e que era "um marinheiro e filho de pais incógnitos, exposto na Roda de Lisboa". Portanto, sob essa premissa, deu-se início ao processo de habilitação matrimonial. ${ }^{8}$

O pároco de Porto Alegre, José Ignácio dos Santos Pereira, afirmou em atestado que era necessário para Gregório o registro de batismo em sua pátria, pois sem o porte desse documento não era admitida a certidão de sua pobreza. Aliás, o pároco afirma e reitera que o "suplicante é pobre" (AHCMPA, Habilitação matrimonial, 1788, fl.40f). O atestado de pobreza era necessário para ser dispensado das taxas cobradas pela paróquia para ascender ao matrimônio e das custas com os banhos. Era uma resolução do bispo do Rio de Janeiro e reafirmada na visitação de $1782 .{ }^{9}$

Apenas em 1790 é que o atestado de batismo de Gregório chegou a Porto Alegre e o processo foi encerrado com a liberação dos noivos para o casório. Mas ainda cabe investigarmos um pouco mais sobre a trajetória de Gregório e, para esse fim, recorrer à documentação da Misericórdia de Lisboa. O menino foi deixado na roda às 14 horas do dia 15 de junho de 1755, com um pequeno enxoval. Naquele mesmo dia foi batizado, recebendo o nome de Gregório (AHSCML, Livro de Entrada de Expostos, 1755, n. $^{\circ} 38$, fl. 57). Logo após batizado, entregaram o exposto a uma ama, a viúva Maria da Conceição, que recebeu salários por dois anos por sua criação (AHSCML, Livro de Entrada de Expostos, 1755, n. $^{\circ} 38$, fl. 57 ) e, após esse período, afirmou criálo gratuitamente, "pelo amor a Deus" (AHSCML, Livro dos Conhecimentos das amas, 1755, n. ${ }^{\circ}$ 56, fl. 25). É interessante frisar que Gregório foi enjeitado meses antes do terremoto que devastou parte de Lisboa, inclusive a própria sede da Misericórdia, em novembro de 1755.

Para termos ideia desse acontecimento, José-Augusto França fez uma análise dos estragos causados pelo terremoto com base em relatos da época. Segundo o autor,

a cidade ficara em parte arrasada pelo sismo e em maior parte foi devastada pelo fogo. Dois terços das ruas ficaram inabitáveis, ou só três mil casas das vinte mil existentes, após o incêndio. Das quarenta igrejas paroquiais, trinta e cinco desmoronaram-se,

\footnotetext{
${ }^{8}$ As normativas tridentinas previam a necessidade da abertura de processo de habilitação matrimonial, um inquérito a que eram submetidos aqueles que desejassem contrair matrimônio mas que não eram nascidos na freguesia, uma forma de evitar a bigamia e relações incestuosas por vínculos de parentesco (FREITAS, 2011, p. 33).

9 No livro de Capítulos de Visitas, o visitador solicita ao reverendo pároco que dispense os impedimentos para os matrimônios de índios e escravos, e, para aqueles que provarem atestado de pobreza, que os banhos sejam gratuitos. Essa menção é depois reiterada na visitação de 1811 (AHCMPA, Livros de Capítulos de Visita Pastoral, 1782, 14 v-15 f).
} 
arderam, ou ficaram em ruínas, só onze conventos dos sessenta e cinco existentes ficaram habitáveis, embora com danos, nenhum dos seis hospitais se salvaram do fogo e trinta e três residências das principais famílias da corte ficaram destruídas (1989, p. 9-10).

Gregório, porém, passou para outro lar, em 1766: o de Manoel de Almeida, seu responsável como amo de ofício. Após a criança completar sete anos, foi entregue a esse mestre de ofício por tempo determinado. ${ }^{10} \mathrm{O}$ alfaiate Manoel de Almeida assinou o termo de obrigação da mesa dos enjeitados, no qual

se obrigou a ensiná-lo, doutriná-lo, como filho, vesti-lo e calçá-lo e a ensinar-Ihe o seu ofício de alfaiate no tempo de seis anos correndo a data deste; e tratalo como seu filho; e acabados os d[itos] seis anos; não estando oficial capaz o d[ito] mestre acabará de ensinar pagando-lhe o seu jornal como a qualquer outro oficial em que não estiver detido corrente para ganhar sua vida conforme destino do d[ito] oficio (AHSCML, Livro das Novas Obrigações, 1766, n. $^{\circ} 4$, fl. 399v);

O exposto Gregório superou os primeiros anos de vida, algo muito raro frente às estatísticas de mortalidade infantil da roda de Lisboa, recebendo um criador e mestre de ofício após atingir certa idade. $O$ alto índice de mortalidade dos expostos nas rodas europeias já foi alvo de inúmeros estudos, e no caso de Lisboa não era diferente, apesar da ausência de estudos estatísticos em razão da falta de documentação. A análise clássica de José Martins nos dá uma ideia. Ele diz que, em 1763, "faleceram 762 crianças; em 1764 faleceram 716; em 1765 a 1767 a mortalidade ascendeu a 1.745" (RIBEIRO, 1998, p.123-124).

Pela trajetória de Gregório, percebemos que ele não seguiu o ofício ensinado, tendo atravessado o Atlântico como marinheiro e ancorado nos portos do Rio de Janeiro, de Rio Grande e em outros da América do Sul. Talvez nosso personagem estivesse ligado às rotas comerciais de navegação. Fazemos essa afirmativa por encontrarmos guias de transportes de escravos em nome de Gregório, agora tido como comerciante, em 1804, quando transportava um escravizado de nome José Benguela para o Rio de Janeiro (AHRS, Guias de escravos, 1804, mç. 66). ${ }^{11}$

$\mathrm{O}$ estudo de Henrique Rodrigues, apesar de tratar do século XIX, nos dá pistas de que migrar poderia ser uma opção já no século XVIII. O autor analisou os passaportes de expostos emitidos para o Brasil em Viana do Castelo. Resgatando

\footnotetext{
${ }^{10}$ Quando o jovem ia aprender um ofício ou era entregue sem qualquer especificação de trabalho, o amo, em geral, ficava obrigado a "sustentar, vestir, calçar, ensinar e educar" o exposto até determinada idade - normalmente, doze anos. As entregas, no caso dos rapazes, se destinavam a aprender um ofício por determinado período de tempo, ao fim do qual passavam a receber soldadas, se fossem considerados aptos (COLEN; MANOEL, 1999, p. 42).

${ }^{11}$ As guias de transporte de escravos eram regulamentadas pela Fazenda Real. Esse documento foi produzido com base no alvará de 14 de outubro de 1751, sendo que a intenção da Coroa portuguesa era impedir a saída indiscriminada de escravos para domínios estranhos ao de Portugal, bem como poderiam servir para garantir a cobrança e o recebimento dos tributos que cabiam à referida Fazenda (Cf. BERUTE, 2006).
} 
diversas trajetórias de expostos que partiram para as terras brasileiras, concluiu que os enjeitados que sobreviveram aos determinismos do abandono e à morte prematura tiveram a opção de atravessar o Atlântico "quer seja pela vontade dos progenitores/ parentes, que 'expulsam' de novo estas crianças para longe de casa, quer seja por iniciativa própria quando adultas" (2010, p. 298).

Após contraírem matrimônio, Gregório e Luisa Dezideria passaram a viver na Freguesia de Viamão. Temos essa constatação porque eles levaram à pia batismal cinco filhos entre 1791 e 1797, sendo que em 1795 batizaram João e José, gêmeos (AHCMPA, Livro de batizados I, II, e III de Viamão, 1791-97, fls.71v, 91 v, 111 v, $132 v)$. É interessante salientar que Gregório não era mais descrito como exposto nos registros de batismos dos filhos, sendo referido como natural de Lisboa e filho de pais incógnitos. O mais curioso é que os padrinhos de seus filhos eram, em sua maioria, militares e as madrinhas eram tratadas como "donas".

Maria Nizza da Silva (2002) alega que o qualitativo "dona" não era mero substantivo qualificador; era atribuído a algumas mulheres que se diferenciavam, em termos de nobreza, das outras. A título de exemplo, o já citado dicionário organizado por Raphael Bluteau inicia o verbete "dona" como "mulher de destaque social". Mais adiante, prossegue: "Dona como derivado do Latim 'Domina' quer dizer Senhoras; com este título de 'Domina' erão tratadas geralmente entre os Romanos mais cortezãos as molheres moças, ou donzellas, sendo nobres" (1727, p. 287). Entretanto, é importante relativizar essa questão, pois poderia se tratar mais de um prestígio entre a comunidade local, reconhecido no direito costumeiro, e não necessariamente um título de nobreza.

Aquestão para a qual chamamos atenção é que as alianças sociais estabelecidas por Gregório, por meio das relações de compadrio, demonstram claramente uma ascensão social, o que ficou mais evidente após percebermos que ele batizou escravos e foi irmão da Irmandade do Santíssimo Sacramento da paróquia de Viamão. ${ }^{12}$

Se o fenômeno da exposição atravessou o Atlântico, os expostos também atravessaram e, quando aqui chegaram, reproduziram práticas sociais. O que queremos ilustrar é que, em 6 de março de 1791, foi exposta, "na noite ao amanhecer do mesmo dia", a menina Anna, em casa do Gregório, que foi padrinho da criança" (AHCMPA, Livro III de batismo, 1791, fl. 72v). Entretanto, Gregório deu a menina para Manuel Clemente Ribeiro criar, e este deu entrada da matrícula na Câmara de Porto Alegre, recebendo salários para o custeio de criação da menina. Infelizmente, Anna não teve o mesmo sucesso de Gregório e faleceu em 11 de julho de 1791, sendo sepultada na "varanda por esmola" da paróquia de Viamão (AHCMPA, Livro III de batismo, 1791, fl. 62v).

Mais inusitado que um exposto sobreviver ao abandono na roda de Lisboa é uma exposta sobreviver e migrar - e pelo Atlântico. É o caso de Izidora Joaquina, que subiu ao altar em 4 de setembro de 1803, em Porto Alegre, para contrair matrimônio com o reinol Francisco Antônio, natural da freguesia de Casais, na Vila de Tomar (AHCMPA,

\footnotetext{
${ }^{12}$ Como instituições sociorreligiosas, as Irmandades eram de extrema importância para a prática cristã e representação de estatuto social: "As Irmandades reuniam boa parcela da sociedade, entre homens, mulheres e crianças. Sustentavam o culto católico e a Igreja propriamente dita, conformando aquilo que muitos chamaram de catolicismo tradicional. Eram integradas por pessoas comuns, simples leigos, interessados em cultuar santos, viver a religião católica, buscar proteção diante das adversidades da vida - ou da morte -, encontrar pessoas, estabelecer relações, praticar a caridade e o auxílio mútuo" (TAVARES, 2008, p. 25).
} 
Livro II de casamentos, 1803, fl. 29 v). Izidora Joaquina e Francisco Antônio, conforme consta na habilitação matrimonial do casal, eram nada menos que "fâmulos na casa do Excelentíssimo Governador desse Continente" (AHCMPA, Habilitação matrimonial, 1803 , fl. 5 f). Essa informação é confirmada pelo rol de confessados de 1803. No fogo do governador Paulo José da Silva Gama, Izidora Joaquina é arrolada entre os cinco criados da casa (AHCMPA, Róis de Confessados e Comungados, 1803, fl.13v).

Na noite do dia 3 de abril de 1764, Izidora foi enjeitada na roda de Lisboa: "Veio para esta roda uma menina envolta em três coeiros, dois de baeta preta e hum de durante cor de azeitona, atados com huma fita de seda". Em 4 de abril, foi batizada e recebeu como padrinho Manoel João, tendo sido entregue a uma ama da roda, Ignes Maria (AHSCML, Livro de Entrada, 1764, n. ${ }^{\circ} 41$, fl. 147). Após um ano de criação, Izidora passou para a ama de leite Maria Brigida, com quem permaneceu por pelo menos um ano. Depois desse período, não soubemos mais de seu paradeiro, até contrair matrimônio na freguesia Madre de Deus de Porto Alegre.

Por fim, é importante mencionar que, assim como Gregório, Izidora também legitima seu estado de pobreza ao pároco para não pagar pelos emolumentos do processo de habilitação matrimonial e pelos custos com o casamento:

[...] porém há que seu est[ado] de probreza que os sujeitou apesar deles avirem na servidão da casa não tem ainda indeferido a com que paguem o seu empenho para os propósitos de seu casamento, cuja pobreza se manifesta a toda esta Vila (AHCMPA, Habilitação matrimonial, 1803, fl. 7v).

O que pretendemos mostrar aqui é como o fenômeno do abandono deve ser pensando de maneira mais ampla quando se trata de Portugal. As conexões com a América portuguesa não se dirigiam apenas a inspirações e orientações nas formas de assistências aos enjeitados, mas também à circulação de pessoas que foram expostas quando crianças. E mesmo práticas corruptíveis, como o contrabando de crianças, se reproduziram com essas conexões.

\section{CONSIDERAÇÕES FINAIS}

A prática de abdicar da criação de uma criança, transferindo essa responsabilidade para outrem, ou deixá-la para a caridade pública ou privada era comum no universo católico. Desde o século XVI, esse fenômeno foi ganhando dimensões significativas no contexto europeu. Com a expansão ibérica, esse fenômeno percorreu novos espaços, sendo propagado na esteira das colonizações.

Nesse sentido, o exercício metodológico aqui teve a proposta de entender esse fenômeno de maneira mais conectada a contextos mais amplos. Não se trata de deixarmos de lado as especificadas locais, mas pensar a prática da exposição de crianças numa longa duração e de maneira conectada a outros espaços pode trazer novas nuances sobre a temática para além dos caminhos já trilhados. Isso pouco tem a ver como a posição colonial, a mestiçagem ou o alto índice de ilegitimidade. Tratase de entender a prática da exposição de crianças como um continuum que, em novo espaço, agrega novas populações (indígenas e africanos) e, logo, novos sentidos. 


\section{REFERÊNCIAS}

ABREU, Laurinda. Misericórdias, Estado Moderno e Império. In: PAIVA, José Pedro (coord.). Portugalia Monumenta Misericordiarum. Lisboa: Centro de Estudos de História Religiosa da Faculdade de Teologia, Universidade Católica Portuguesa, União das Misericórdias Portuguesas, 2017. p. 245-277. v. 10.

ALENCASTRO, Luiz Felipe de. O trato dos viventes: formação do Brasil no Atlântico Sul. São Paulo: Companhia das Letras, 2000.

ARMITAGE, David. Três conceitos de História Atlântica. História Unisinos, São Leopoldo. v. 18, n. 2, p. 206-217, 2014.

ARQUIVO HISTÓRICO CÚRIA METROPOLITANA DE PORTO ALEGRE, Freguesia de Nossa Senhora Madre de Deus (Porto Alegre). Habilitação matrimonial de Gregório José da Rosa e Luísa Desidéria da Silveira. [manuscrito]. Porto Alegre, 1788, 72f., n² 27, Cx.45.

ARQUIVO HISTÓRICO CÚRIA METROPOLITANA DE PORTO ALEGRE , Freguesia de Nossa Senhora Madre de Deus (Porto Alegre). Habilitação matrimonial de Francisco Antônio e Izidora Joaquina. [manuscrito]. Porto Alegre, 1803, 34f., nº 27 , Cx.90.

ARQUIVO HISTÓRICO CÚRIA METROPOLITANA DE PORTO ALEGRE , Freguesia de Nossa Senhora Madre de Deus (Porto Alegre). Livro de Capítulos de Visita Pastoral. [manuscrito]. Porto Alegre, 1782, (1V).

ARQUIVO HISTÓRICO CÚRIA METROPOLITANA DE PORTO ALEGRE , Freguesia de Nossa Senhora Madre de Deus (Porto Alegre). Livros de registros de casamentos (1772-1850). [manuscrito]. Porto Alegre, 1772-1835, (4V).

ARQUIVO HISTÓRICO CÚRIA METROPOLITANA DE PORTO ALEGRE , Freguesia de Nossa Senhora Madre de Deus (Porto Alegre). Róis de Confessados e Comungados. [manuscrito]. Porto Alegre, Ano: 1803, (1V).

ARQUIVO HISTÓRICO DA SANTA CASA DA MISERICÓRDIA DE LISBOA, Livro dos Conhecimentos das amas. [manuscrito]. n. ${ }^{\circ}$ 56, fl. 25 (Cota 054), 1755.

ARQUIVO HISTÓRICO DA SANTA CASA DA MISERICÓRDIA DE LISBOA, Livro de Entrada de Expostos. [manuscrito]. n. ${ }^{\circ} 38-41$ fls. 57-58v; 147-148v, n $322 ;$ n. $^{\circ} 518$ (Cota 033; 036), 1755.

ARQUIVO HISTÓRICO DA SANTA CASA DA MISERICÓRDIA DE LISBOA, Livro das Novas Obrigações. [manuscrito]. n. ${ }^{\circ}$ 4, fl.399v. (Cota 005), 1766.

ARQUIVO HISTÓRICO DA SANTA CASA DA MISERICÓRDIA DE LISBOA, Avisos e Ordens da Mesa. [manuscrito]. Livro 01, 1779, fls. 90-105v. 
ARQUIVO HISTÓRICO DO RIO GRANDE DO SUL, Documentação Avulsa da Fazenda, Guias de escravos. [manuscrito]. Porto Alegre, 1786-1814, mç. 66.

ARQUIVO HISTÓRICO ULTRAMARINO, Concelho Ultramarino-Angola, Vila Vitória de Massangano. AHU-Angola, cx. 7, doc. 37 e 33. AHU_CU_001, Cx. 7, D. 779, 1661.

ARQUIVO HISTÓRICO ULTRAMARINO, Concelho Ultramarino-Moçambique. [ant. 1830, Maio, 25]. AHU-Moçambique, cx. 232, doc. 59. AHU_CU_064, Cx., D.

BERUTE, Gabriel Santos. Dos escravos que partem para os portos do sul: características do tráfico negreiro no Rio Grande de São Pedro do Sul, c.1790 - c.1825. 2006. 200 p. Dissertação (Mestrado em História) - Programa de PósGraduação em História, Instituto de Filosofia e Ciências Humanas, Universidade Federal do Rio Grande do Sul, Porto Alegre, 2006.

BIBILIOTECA NACIONAL DE PORTUGAL, Santa Casa da Misericórdia (Lisboa). Compromisso da Misericórdia de Lisboa. Lisboa: por António Alvarez, 1640.

BICALHO, Maria Fernanda. As câmaras ultramarinas e o governo do Império. In: FRAGOSO, João Luís R.; BICALHO, Maria Fernanda; GOUVÊA, Maria de Fátima. O antigo regime nos trópicos: a dinâmica imperial portuguesa (séculos XVI - XVIII). Rio de Janeiro: Civilização Brasileira, 2001. p. 189-221.

BLUTEAU, Rafael. Supplemento ao Vocabulario Portuguez e latino (Parte 1: Letras A-L) Lisboa: Na Officina de Joseph Antonio da Sylva, p. 377, 1727. Disponível em: "https://digital.bbm.usp.br/view/?45000009348\&bbm/5448\#page/511/mode/1up". Acesso em: 20 fev. 2021.

BOXER, Charles H. O Império marítimo português 1415-1825. São Paulo: Companhia das Letras, 2002.

BRAGA, Isabel M. R. Mendes Drumond. Fugindo dos "grilhões do cativeiro": os expostos pretos e pardos na casa da roda da Misericórdia de Lisboa (1780-1807). Revista de História da Sociedade e da Cultura, Coimbra, n. 11, p. 223-247, 2011.

CENTRO HISTÓRICO-CULTURAL DA SANTA CASA. Livro I de Atas da Mesa Administrativa. [manuscrito]. 1815-1828, (1V).

COATES, Timothy J. Degredados e Órfãs: colonização dirigida pela coroa no império português, 1550-1755. Lisboa: Comissão Nacional para as Comemorações dos Descobrimentos Portugueses, 1998.

COIMBRA. Ordenações Manuelinas. Edição fac-símile da edição feita na Real Imprensa da Universidade de Coimbra, no ano de 1797. Lisboa: Fundação Calouste Gulbenkian, 1984. 
COLEN, Luisa Barbosa; MANOEL, Francisco D'Orey. Os expostos e desamparados na misericórdia de Lisboa. Cidade Solidária - Revista da Santa Casa da Misericórdia de Lisboa, Lisboa, n. 2, p. 40-48, 1999.

DAVIS, Natalie Zemon. O retorno de Martin Guerre. Rio de Janeiro: Paz e Terra, 1987.

DOMINGUES, Ângela; MOURA, Denise. Introdução. In: RUSSELL-WOOD, Anthony J. R. Histórias do Atlântico português. São Paulo: Fundação Editora Unesp, 2014. p. 11-12.

FRANCO, Renato. Pobreza e caridade leiga: as Santas Casas de Misericórdia na América portuguesa. 2011. Doutorado (História Social) - Faculdade de Filosofia, Letras e Ciências Humanas, Universidade de São Paulo, São Paulo, 2011.

FRANCO, Renato. A piedade dos outros: o abandono de recém-nascidos em uma vila colonial, século XVIII. Rio de Janeiro: FGV, 2014.

FRANCO, Renato. Riqueza, pobreza e infância: o reformismo ilustrado português e a utilidade dos expostos. História, Ciências, Saúde-Manguinhos, Rio de Janeiro, v. 26, (Supl.), p. 109-126, dez. 2019.

FRANÇA, José-Augusto. A reconstrução de Lisboa e a arquitectura pombalina. 3 ed. Lisboa: Instituto de Cultura e Língua Portuguesa, 1989.

FREITAS, Denize Terezinha Leal. O casamento na Freguesia Madre de Deus de Porto Alegre: a população livre e suas relações matrimoniais de 1772-1835. 2011. 213 f. Dissertação (Mestrado em História) - Escola de Humanidades, Universidade do Vale do Rio dos Sinos, São Leopoldo, RS, 2011.

GINZBURG, Carlo. O fio e os rastros: verdadeiro, falso, fictício. São Paulo:

Companhia das Letras, 2007.

MARCÍLIO, Maria Luiza. História social da criança abandonada. São Paulo: Hucitec, 1998.

NEUMANN, Eduardo; KÜHN, Fábio (org.). Projeto Resgate de Fontes Paroquiais: Porto Alegre e Viamão (século XVIII) - Batismos e Óbitos. Porto Alegre: UFRGS, 2000. [CD-ROM]

PUTNAM, Lara. To Study the Fragments/Whole: Microhistory and the Atlantic World. Journal of Social History, Fairfax County, v. 39, n. 3, p. 615-630, 2006.

RIBEIRO, Victor. A Santa Casa da Misericórdia de Lisboa: subsídios para a sua história. Reprodução fac-similada da edição de 1902. Lisboa: Academia das Ciências de Lisboa, 1998. 
RODRIGUES, Henrique. Sobrevivências e trajectórias de expostos emigrados para o Brasil. In: VENANCIO, Renato Pinto (org.). De Portugal ao Brasil: uma história social do abandono de crianças. São Paulo; Belo Horizonte: Alameda; Editora Puc Minas, 2010. p. 297-338.

RUSSELL-WOOD, Anthony. Fidalgos e filantropos: a Santa Casa de Misericórdia da Bahia, 1550-1775. Brasília: Editora UnB, 1981.

RUSSELL-WOOD, Anthony. Escravos e libertos no Brasil colonial. Rio de Janeiro: Civilização Brasileira, 2005.

RUSSELL-WOOD, Anthony. Um mundo em movimento: os portugueses na África, Ásia e América (1415-1808). Lisboa: Difel, 2006.

RUSSELL-WOOD, Anthony. O Império português: 1415-1808 - o mundo em movimento. Lisboa: Clube do Autor, 2016.

SÁ, I. dos G. A circulação de crianças na Europa do Sul: o caso dos expostos do Porto no século XVIII. Lisboa: Fundação Calouste Gulbekian/JNICT, 1995.

SÁ, Isabel dos Guimarães. Abandono de crianças, identidade e lotaria: reflexões em torno de um inventário. In: SANTA CASA DA MISERICÓRDIA DE LISBOA. Inventário da Criação dos Expostos do Arquivo Histórico da Santa Casa da Misericórdia de Lisboa. Lisboa: Santa Casa da Misericórdia de Lisboa, 1998. p. IX-XXII.

SÁ, Isabel dos Guimarães. As Misericórdias portuguesas: séculos XVI a XVIII. Rio de Janeiro: FGV, 2013.

SCOTT, Ana Silvia Volpi; BERUTE, Gabriel Santos. Gentes das Ilhas: repensando a migração do Arquipélago dos Açores para a capitania do Rio Grande de São Pedro no século XVIII. In: SCOTT, Ana Silvia Volpi; BERUTE, Gabriel Santos; MATOS, Paulo Teodoro de (org.). Gente das ilhas: rrajetórias transatlânticas dos Açores a Rio Grande de São Pedro entre as décadas de 1740-1790. São Leopoldo: Oikos, 2011. p. 105-146.

SCOTT, Rebecca J. Small-Scale Dynamics of Large-Scale Processes. The American Historical Review, Washington, v. 105, n. 2, p. 472-579, 2000.

SCOTT, Rebecca J.; HÉBRARD, Jean M. Provas de liberdade: uma odisseia atlântica na era da emancipação. Campinas: Editora da Unicamp, 2014.

SEABRA, Leonor Dias de. (org.). O compromisso da Santa Casa da Misericórdia da Irmandade de Goa do anno de 1595. Macau: Universidade de Macau, 2005.

SEABRA, Leonor Dias de. A mulher na Misericórdia de Macau. Administração, Macau, n. 76, v. XX, p. 605-617, 2007. 
SILVA, Antonio de Moraes. Diccionário da Língua Portugueza. Lisboa: Empreza Litteraria Fluminense, 1798.

SILVA, Maria Beatriz Nizza da. Donas e plebeias na sociedade colonial. Lisboa: Editorial Estampa, 2002.

SLACK, Paul. The English poor law: 1531-1782. Cambridge: Cambridge University Press, 1995.

TAVARES, Mauro Dillmann. Irmandades, Igreja e devoção no sul do Império do Brasil. São Leopoldo: Oikos, 2008.

VAZ, Francisco de Assis. Algumas considerações sobre os expostos: fragmento da obra do Barão de Gerando. Porto: Typ. da Revista, 1843.

VENANCIO, Renato. Famílias abandonadas: assistência à criança de camadas populares no Rio de Janeiro e em Salvador - séculos XVIII e XIX. Campinas: Papirus, 1999.

WADI, Yonissa Marmitt. Palácio para guardar doidos: uma história das lutas pela construção do hospital de alienados e da psiquiatria no Rio Grande do Sul. Porto Alegre: Editora da UFRGS, 2002.

XAVIER, Ângela Barreto. A invenção de Goa: poder imperial e conversões culturais nos séculos XVI e XVII. Lisboa: Imprensa de Ciências Sociais, 2008.

\section{NOTAS DE AUTOR}

\section{ENDEREÇO PARA CORRESPONDÊNCIA}

Av. Theodomiro Porto da Fonseca, 2173, 401A, 93022-665, São Leopoldo, RS, Brasil.

\section{ORIGEM DO ARTIGO}

Extraído da tese "A assistência e a exposição de crianças na formação de um território (Rio Grande de São Pedro, séculos XVIII e XIX)", apresentada ao Programa de Pós-Graduação em História da Universidade do Vale do Rio dos Sinos, em 2019.

\section{FINANCIAMENTO}

Coordenação de Aperfeiçoamento de Pessoal de Nível Superior, Programa de Suporte à Pós-Graduação de Instituições Comunitárias de Ensino Superior (CAPES/PROSUC) e Programa Doutorado-Sanduíche no Exterior-CAPES (PDSE-CAPES).

\section{APROVAÇÃO DE COMITÊ DE ÉTICA EM PESQUISA}

Não se aplica.

\section{CONFLITO DE INTERESSES}

Não houve conflito de interesses. 


\section{LICENÇA DE USO}

(c) Jonathan Fachini da Silva. Este artigo está licenciado sob a Licença Creative Commons CC-BY. Com essa licença você pode compartilhar, adaptar, criar para qualquer fim, desde que atribua a autoria da obra.

\section{PUBLISHER}

Universidade Federal de Santa Catarina. Programa de Pós-Graduação em História. Portal de Periódicos UFSC. As ideias expressadas neste artigo são de responsabilidade de seus autores, não representando, necessariamente, a opinião dos editores ou da universidade.

\section{EDITORES}

Flávia Florentino Varella (Editora-chefe)

Tiago Kramer de Oliveira

Waldomiro Lourenço da Silva Júnior

\section{HISTÓRICO}

Recebido em: 4 de fevereiro de 2020

Aprovado em: 28 de julho de 2020

Como citar: SILVA, Jonathan Fachini da. Exposição de crianças e travessias atlânticas: o trânsito de práticas e pessoas para o extremo sul da América Portuguesa (1750-1810). Esboços, Florianópolis, v. 28, n. 48 , p. 509-530, maio/ago. 2021. 